(c) American Dairy Science Association, 2003.

\title{
Seasonality of Days Open in US Holsteins
}

\author{
S. Oseni, I. Misztal, S. Tsuruta, and R. Rekaya \\ Department of Animal and Dairy Science \\ University of Georgia, Athens, 30602
}

\section{ABSTRACT}

The objectives of this study were to establish a pattern for the seasonality of days open (DO) by state and region within the United States and to present statistics on regional trends for DO. Data included 8,676,915 records on DO for Holsteins from 1997 to 2002 covering all regions of the United States. Fixed effects in the model included herd, parity, milk-class, state $\times$ month of calving $(\mathrm{MOC})$, year of calving $\times \mathrm{MOC}$, and parity $\times$ MOC. Least squares means of DO were highest for calvings in March and lowest for calvings in September. The highest mean DO of $155 \mathrm{~d}$ was recorded in the Southeast, while the mean DO for the Midwest, Northeast, Northwest, and Southwest were 142, 141, 140, and $137 \mathrm{~d}$, respectively. Variation in monthly averages of DO was highest in Southeast with a range of $51 \mathrm{~d}$, and less than $25 \mathrm{~d}$ in all the other regions. Seasonality of calving was defined as the ratio of the fewest to the most calvings in months. The SOC was $\geq 60 \%$ in Southeast and $\leq 23 \%$ in the other regions. Selected states: Texas, Oklahoma, and Arizona in the Southwest and Missouri, Kansas, and Kentucky in the Midwest showed patterns of variation in monthly averages and seasonality of calving similar to those of Southeast. Distributions of DO were bimodal for some months of calving due to postponed breeding during the hot season or depressed fertility as a result of thermal stress; the second mode at $>200 \mathrm{~d}$ was highest in the Southeast but also could be observed in Texas, Wisconsin, and California. High level of heat stress for DO exists in the Southeast and in selected states of the Midwest and the Southwest; these regions contribute less than $10 \%$ of national records. A methodology for analyzing DO especially under heat stress needs to consider effects of intentionally delayed breeding-by using a model that accounts for bimodality, for example.

(Key words: days open, heat stress, seasonality, month of calving)

Abbreviation key: $\mathbf{D O}=$ days open, $\mathbf{S E}=$ Southeast , $\mathbf{S W}=$ Southwest, $\mathbf{N E}=$ Northeast, $\mathbf{N W}=$ Northwest,

Received April 30, 2003.

Accepted July 30, 2003.

Corresponding author: S. Oseni; e-mail: soseni@arches.uga.edu.
MW $=$ Midwest, $\mathbf{S O C}=$ seasonality of calving, $\mathbf{M O C}=$ month of calving, VMA = variation in monthly averages.

\section{INTRODUCTION}

The declining trend in fertility traits in dairy herds over time especially in the Southeastern United States has been of growing concern (Silvia, 1998; Wasburn et al., 2002). Reasons for this trend have been largely attributed to the antagonistic relationship between yield and fertility traits (Lucy and Crooker, 2001), which is further exacerbated by high thermal stress suffered during the hot seasons of the year (Wolfenson et al., 2000).

One of the measures of fertility in dairy cattle is days open (DO) - a complex trait that is affected by many factors such as season of calving, management policies, herd size, production level, parity, and AI techniques. Even though DO has become accepted as one of the best single measures of reproductive efficiency (Norman et al., 2002), some concerns have been raised about this approach principally because of the large management intervention through deliberate delayed rebreeding, use of bST, and in some instances, no evidence or proof of the results of matings on which DO is based (Weller and Ron, 1992). However, the use of veterinary-confirmed records or using a formula that involves calving interval may help to correct some anomalies connected with the use of DO.

Several studies (Oleggini et al., 2001; Washburn et al., 2002; VanRaden et al., 2002) have reported differences between and within regions in DO, with higher mean DO reported for southern states of the United States. VanRaden et al. (2002) specifically examined the varying trend of DO by month of calving (MOC), whereas the other authors only compared the absolute value of $\mathrm{DO}$ by region. The first approach is crucial for genetic evaluations because the performance of animals can be evaluated along a trajectory and the genetic trends for DO can be monitored over time. Also, if monthly fluctuations in DO are due primarily to heat stress, a selection to reduce the fluctuations will increase heat tolerance of animals. 


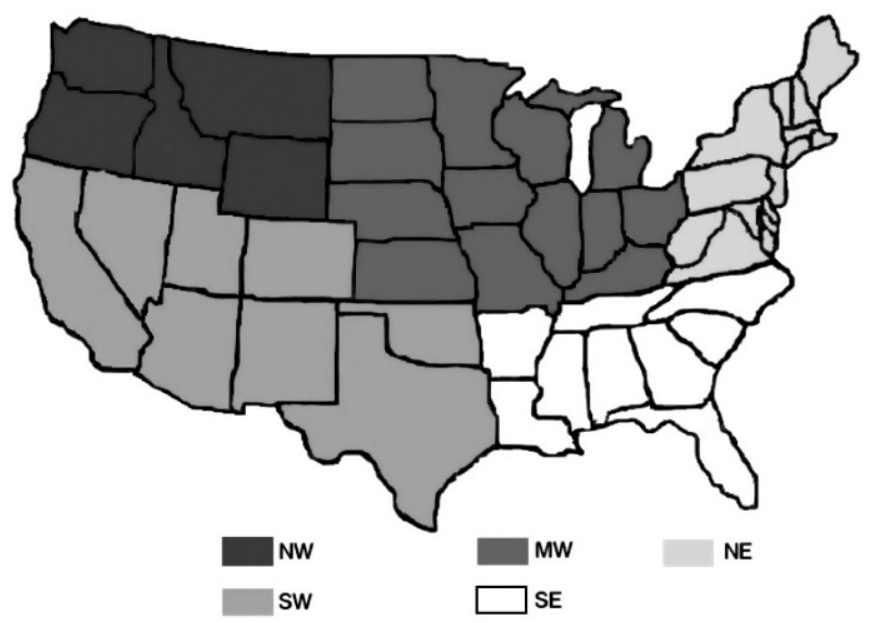

Figure 1. Map of the United States showing the distribution of states by region: Southeast (SE), Southwest (SW), Northeast (NE), Northwest (NW), and Midwest (MW).

While there were a few studies that looked at the pattern of decline in fertility and reproductive performance in specific states (e.g. Thatcher, 1974; Cavestany et al., 1985 for FL; Washburn et al., 2002 for states in the south; Silvia, 1998 for KY; Ray et al., 1992; Stott, 1961 for AZ; Gwazdauskas et al., 1981 for VA; Stevenson et al., 1983 for KS), no study examined the pattern and distribution of heat stress by state across all regions of the United States. Such a study would provide a framework for national genetic evaluation for fertility under heat stress. Thus, the objectives of this study were to establish a pattern for the seasonality of DO by state and region within the United States and to present statistics on seasonal trends for DO.

\section{MATERIALS AND METHODS}

Data were obtained from the AIPL of the USDA and included 8,676,915 records on 2,375,001 Holstein cows calving between 1997 and 2002. Data covered most states of the United States and consisted of multiple parities. Variables in the dataset included herd, DO, calving dates, parity, milk yield, and SCC. Days open was already computed in the datasets; details of these computations are described by VanRaden et al. (2002). In data editing, DO greater than $20 \mathrm{~d}$ and less than 50 $\mathrm{d}$ were set to $50 \mathrm{~d}$. Days open greater than $365 \mathrm{~d}$ were not used in the analyses. Also, parities greater than 5 were not included. Milk classes were defined as follows: class $1: \leq 8172 \mathrm{~kg}$; class $2:>8172 \mathrm{~kg}$ and $\leq 9534 \mathrm{~kg}$; class 3: $>9534 \mathrm{~kg}$ and $\leq 10,556 \mathrm{~kg}$; class $4:>10,556 \mathrm{~kg}$ and $\leq 11,577 \mathrm{~kg}$; and class 5: >11,577 kg. Regions used in the analyses were as defined in Figure 1.

\section{Statistical Analyses}

Data were analyzed using the GLM procedure of SAS (1999). The first analysis was done using DO as a dependent variable and the fixed effects of parity, herd, year of calving, milk class and state $\times$ MOC, and milk class $\times$ MOC as independent variables. The second analysis was similar to the first except that state $\times$ MOC was replaced by region $\times$ MOC effect. In order to generate least squares means by MOC for each state, PROC GLM was run individually on the records for that state. However, for regions, all the records for all the states in that region were pooled. These steps were to facilitate the comparison of the least squares means of DO by MOC between states and between regions. Least squares means of DO by MOC were also generated for parities, year of calving and milk class categories. Seasonality of calving (SOC) was defined as follows:

$$
\mathrm{SOC}=1-
$$

Number of calvings in the month with the fewest calvings) Number of calvings in the month with the most calvings .

Range of DO was calculated as the difference between the least squares means for DO in the months of calving with the highest and lowest DO. Calculations of both SOC and range were applied to all records for each state and region.

\section{RESULTS AND DISCUSSION}

Figure 1 presents the assignment of states to regions, and Table 1 shows the distribution of records, number of herds, means and ranges of DO, and the SOC by region and states within regions. Additionally, Figures 2 and 3 summarize the information from the table in graphical forms. Means and ranges of DO across seasons were highest for Southeast (SE), while there were small differences in mean DO for Northeast (NE), Northwest (NW), and Midwest (MW). Southwest had the lowest mean DO $(137 \mathrm{~d})$. Within regions, wide DO ranges observed for the SE may imply that the effect of season on mating and calving patterns is more pronounced in this region compared with other regions. The SOC followed the same trend. Southeast states had the highest seasonality value of 0.60 , whereas all other regions had SOC values $<0.23$.

States with high SOC $(>0.50)$ also recorded wide DO ranges $(\geq 42 \mathrm{~d})$. This trend was observed across most regions and may reflect a cause-and-effect relationship. A seasonality of 0.50 implies that about $50 \%$ of the cows bred during the hot season calved in the spring. This could be an indication of the effect of either deliberate delayed rebreeding of some cows or low conception rate 
Table 1. Seasonality of calving, means, and ranges of days open (DO) by region.

\begin{tabular}{|c|c|c|c|c|c|}
\hline $\begin{array}{l}\text { States } \\
\text { Region }^{1}\end{array}$ & $\begin{array}{l}\text { Number } \\
\text { of records }\end{array}$ & $\begin{array}{l}\text { Number } \\
\text { of herds }\end{array}$ & $\begin{array}{l}\text { Seasonality } \\
\text { of calving }\end{array}$ & $\begin{array}{l}\text { Mean } \\
\text { DO }\end{array}$ & $\begin{array}{l}\text { Range } \\
\text { of } \mathrm{DO}^{3}\end{array}$ \\
\hline GA & 50,759 & 142 & 0.64 & 156 & 52 \\
\hline FL & 48,318 & 92 & 0.51 & 159 & 36 \\
\hline $\mathrm{NC}$ & 70,057 & 134 & 0.52 & 155 & 47 \\
\hline $\mathrm{SC}$ & 27,123 & 64 & 0.65 & 152 & 63 \\
\hline $\mathrm{TN}$ & 48,091 & 137 & 0.60 & 155 & 54 \\
\hline $\mathrm{AR}$ & 8655 & 74 & 0.70 & 154 & 61 \\
\hline $\mathrm{AL}$ & 13,068 & 42 & 0.74 & 152 & 64 \\
\hline LA & 20,815 & 120 & 0.78 & 153 & 69 \\
\hline MS & 20,018 & 71 & 0.74 & 155 & 67 \\
\hline All SE & 306,905 & 382 & 0.60 & 155 & 51 \\
\hline CA & $2,251,374$ & 764 & 0.27 & 135 & 17 \\
\hline $\mathrm{CO}$ & 85,838 & 79 & 0.18 & 148 & 17 \\
\hline NM & 80,554 & 38 & 0.17 & 134 & 16 \\
\hline NV & 24,513 & 22 & 0.29 & 143 & 21 \\
\hline OK & 23,401 & 100 & 0.61 & 157 & 49 \\
\hline $\mathrm{TX}$ & 176,853 & 271 & 0.51 & 150 & 47 \\
\hline UT & 100,292 & 213 & 0.26 & 147 & 15 \\
\hline $\mathrm{AZ}$ & 140,052 & 58 & 0.60 & 134 & 39 \\
\hline All SW & $2,660,103$ & 987 & 0.23 & 137 & 18 \\
\hline VT & 123,846 & 496 & 0.26 & 137 & 24 \\
\hline VA & 179,029 & 313 & 0.41 & 146 & 37 \\
\hline RI & 774 & 6 & 0.55 & 145 & 41 \\
\hline PA & 769,777 & 2468 & 0.23 & 141 & 25 \\
\hline CT & 35,794 & 122 & 0.24 & 140 & 26 \\
\hline $\mathrm{DE}$ & 12,248 & 35 & 0.55 & 151 & 44 \\
\hline MA & 29,506 & 130 & 0.26 & 142 & 26 \\
\hline MD & 118,252 & 383 & 0.36 & 147 & 30 \\
\hline $\mathrm{ME}$ & 37,630 & 160 & 0.24 & 141 & 23 \\
\hline $\mathrm{NH}$ & 30,339 & 110 & 0.27 & 140 & 32 \\
\hline NJ & 21,573 & 110 & 0.31 & 149 & 32 \\
\hline NY & 516,732 & 1278 & 0.27 & 138 & 21 \\
\hline All NE & $2,153,012$ & 2755 & 0.23 & 141 & 25 \\
\hline ID & 175,516 & 214 & 0.28 & 138 & 17 \\
\hline MT & 20,468 & 66 & 0.42 & 141 & 13 \\
\hline OR & 103,267 & 188 & 0.20 & 142 & 13 \\
\hline WA & 216,068 & 235 & 0.21 & 141 & 15 \\
\hline WY & 1863 & 10 & 0.71 & 135 & 25 \\
\hline All NW & 517,171 & 489 & 0.22 & 140 & 14 \\
\hline IA & 204,542 & 784 & 0.22 & 147 & 26 \\
\hline IL & 108,337 & 402 & 0.37 & 153 & 34 \\
\hline IN & 91,000 & 361 & 0.33 & 149 & 32 \\
\hline $\mathrm{KS}$ & 65,530 & 191 & 0.44 & 154 & 45 \\
\hline $\mathrm{KY}$ & 39,588 & 185 & 0.57 & 154 & 42 \\
\hline MI & 290,107 & 820 & 0.29 & 142 & 23 \\
\hline MN & 762,387 & 1847 & 0.20 & 143 & 23 \\
\hline MO & 61,664 & 303 & 0.55 & 152 & 47 \\
\hline ND & 15,003 & 71 & 0.34 & 148 & 28 \\
\hline SD & 40,472 & 182 & 0.20 & 151 & 26 \\
\hline $\mathrm{NE}$ & 55,744 & 165 & 0.25 & 153 & 30 \\
\hline $\mathrm{OH}$ & 251,154 & 703 & 0.29 & 146 & 24 \\
\hline WI & $1,036,166$ & 2153 & 0.22 & 134 & 18 \\
\hline WV & 148,094 & 67 & 0.33 & 148 & 31 \\
\hline All MW & $3,039,724$ & 2801 & 0.21 & 142 & 24 \\
\hline All States & $8,676,915$ & 5645 & 0.30 & 142 & 25 \\
\hline
\end{tabular}

${ }^{1} \mathrm{SE}=$ Southeast, $\mathrm{SW}=$ Southwest, $\mathrm{NE}=$ Northeast, $\mathrm{NW}=$ Northwest, and MW = Midwest.

${ }^{2}$ Seasonality of calving $=$ (minimum number of calvings in a month) $/$ (maximum number of calvings in a month).

${ }^{3}$ Range $=$ difference between $\max$ and $\min$ DO.

associated with seasonal thermal stress. Cows for which breeding is delayed or cows with depressed fertility resulting from heat stress necessarily have to have longer DO.
For California, the pattern of variation of DO by season was unexpectedly small. This state had over 2 million records (78\% of the total records from the SW) and is also notable for large herd sizes. It could be that dairy 


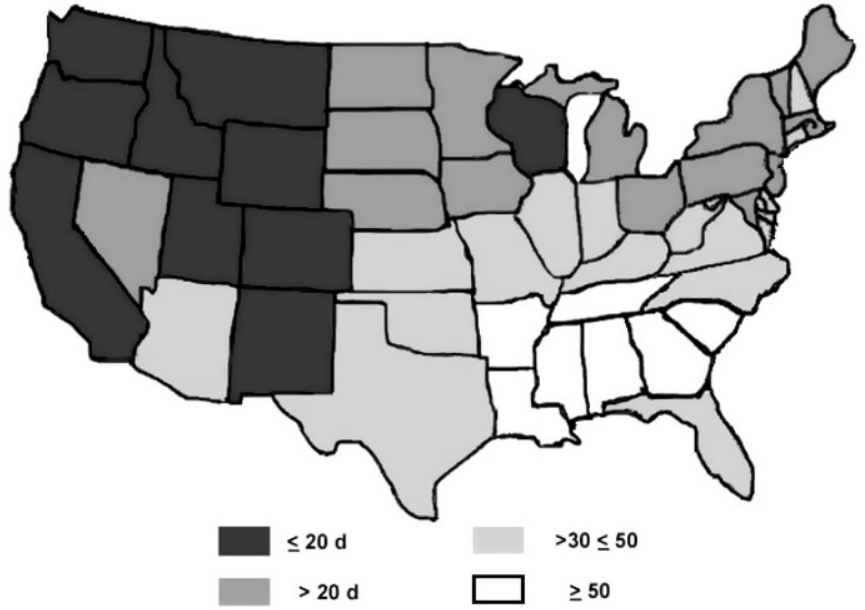

Figure 2. Distribution of states by ranges of days open.

units are more efficiently managed in terms of improved heat detection procedures, estrus synchronization, and prompt AI services. When animals in heat are promptly mated, this compensates for lower fertility in herds of high producing cows (Nebel and McGilliard, 1993; Lucy and Crooker, 2001; Rajala-Schultz and Frazer, 2003).

Florida had the smallest range for DO among SE states even though the overall mean DO (159 d) was among the highest in that region. One interpretation for this trend is that in Florida, animals are constantly under heat stress and as a result, climatic factors do not fluctuate between extremes when compared to other states (W. W. Thatcher, personal communications).

All states with $>500,000$ records (California, New York, Pennsylvania, Minnesota, and Wisconsin) had low SOC $(<0.27)$ and small DO range $(<25 \mathrm{~d})$ across

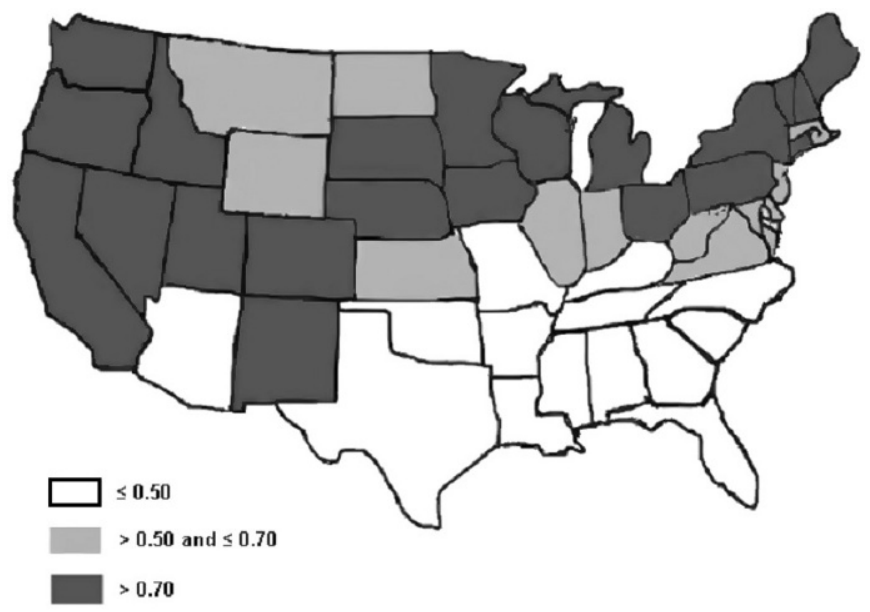

Figure 3. Distribution of states by seasonality of calving.

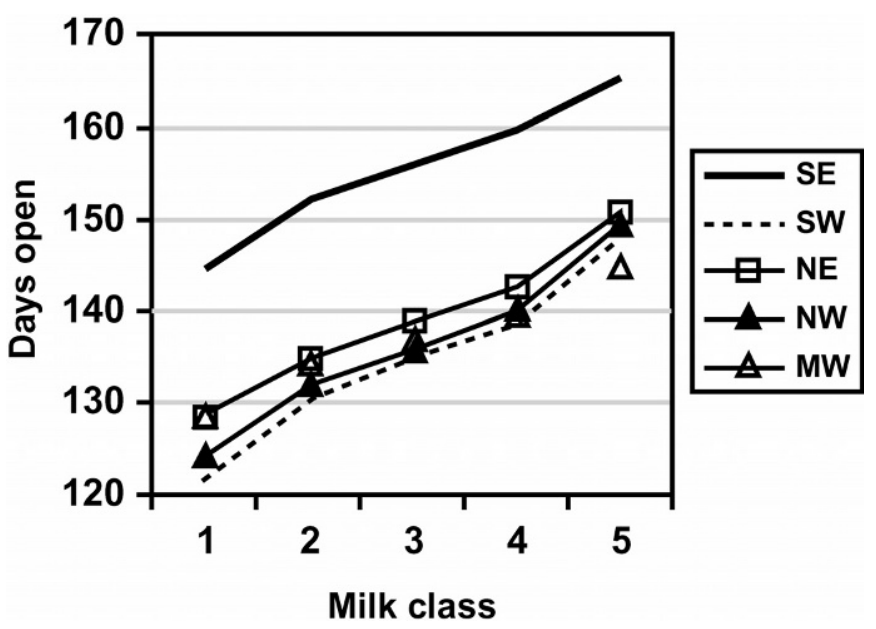

Figure 4. Least squares means of days open by milk classes for five regions: Southeast (SE), Southwest (SW), Northeast (NE), Northwest (NW), and Midwest (MW).

seasons. These states contribute about $53 \%$ of data in this study. In contrast, states with SOC greater than 0.50 and a DO range greater than $36 \mathrm{~d}$ (all states of the SE, Texas, Arizona, Kentucky, Delaware, Oklahoma, and Missouri), contribute only about $8 \%$ of records.

Figure 4 presents least squares means of DO for each milk-class category by region. Milk yield classes were included in the model because of the negative genetic correlations between milk yield and reproductive traits reported by several investigators (Hermas et al., 1987; Pryce and Veerkamp, 2001; Washburn et al., 2002). Least squares means for DO increased with milk yield, the largest mean DO was recorded for the highest yielding class $(\geq 11,577 \mathrm{~kg})$, and the magnitude of change was similar for all regions. This result could be connected with the antagonistic relationship between yield and fertility/reproductive efficiency as reported by several authors (Seykora and McDaniel, 1983; Faust et al., 1988; Nebel and McGilliard, 1993; Lucy and Crooker, 2001).

Figure 5 shows least squares means of DO for different MOC in the SE, SW, NE, MW, and NW. In general, the highest DO were for cows calving in JanuaryMarch, and the lowest for cows calving in July-September. There are two patterns of variations: large "sinusoidal" and small "dipped." The last pattern was observed for states with moderate summer climate due to geographical position (e.g., Wisconsin), or high altitude (California, Colorado, New Mexico). The patterns may reflect the two extremes; all other states appear to fall into some intermediate categories as indicated by the seasonal ranges of $\mathrm{DO}$ (Table 1 ). 
a) GA, FL, NC, TN

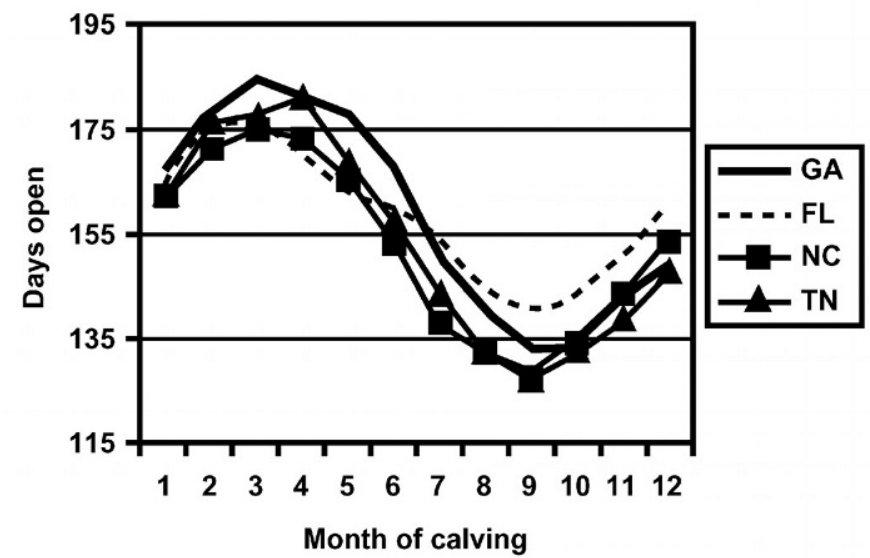

c) NY, PA, VA, NH

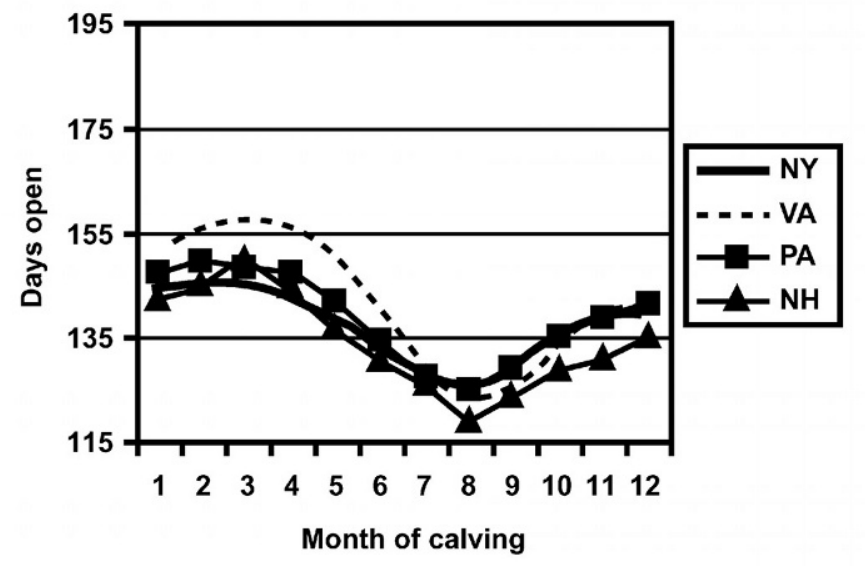

e) WA, ID, MT, OR

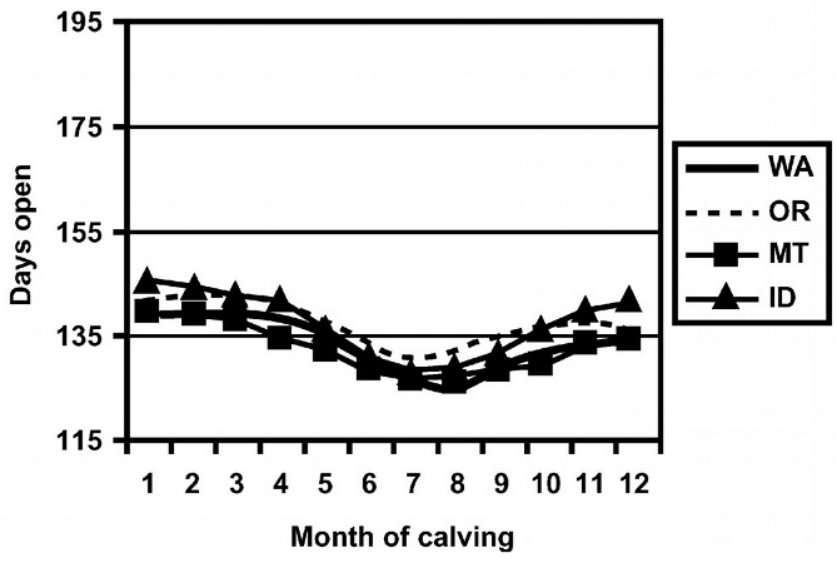

b) CA, CO, TX, OK

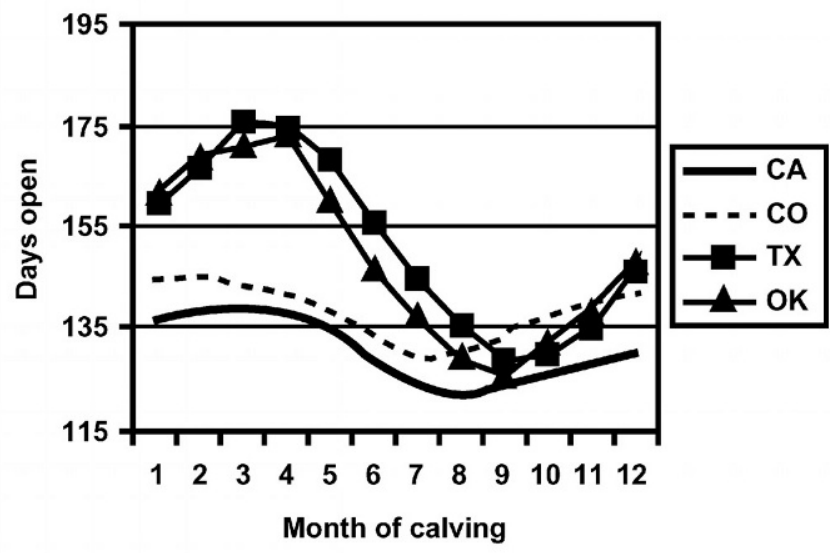

d) WI, MO, KS, KY

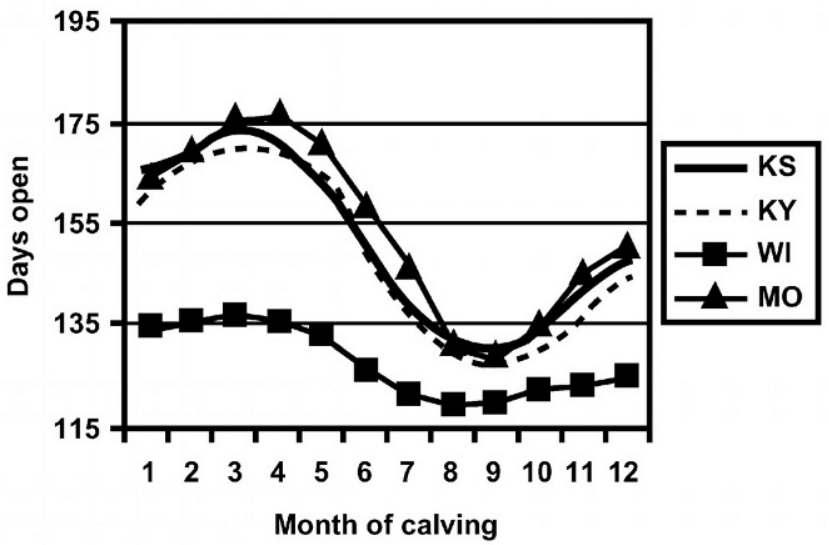

Figure 5. Least squares means for days open by region: a) Southeast (GA, FL, TN, and NC), b) Southwest (CA, CO, OK, and TX), c) Northeast (NY, PA, NH, and VA), d) Midwest (WI, MO, KY, and KS), and e) Northwest (WA, OR, MT, and ID). 
a)

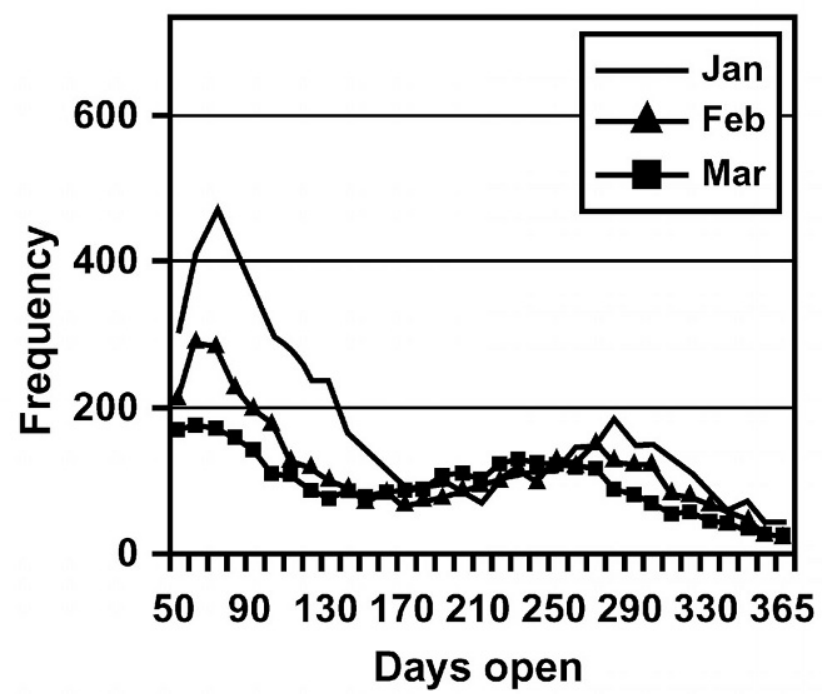

c)

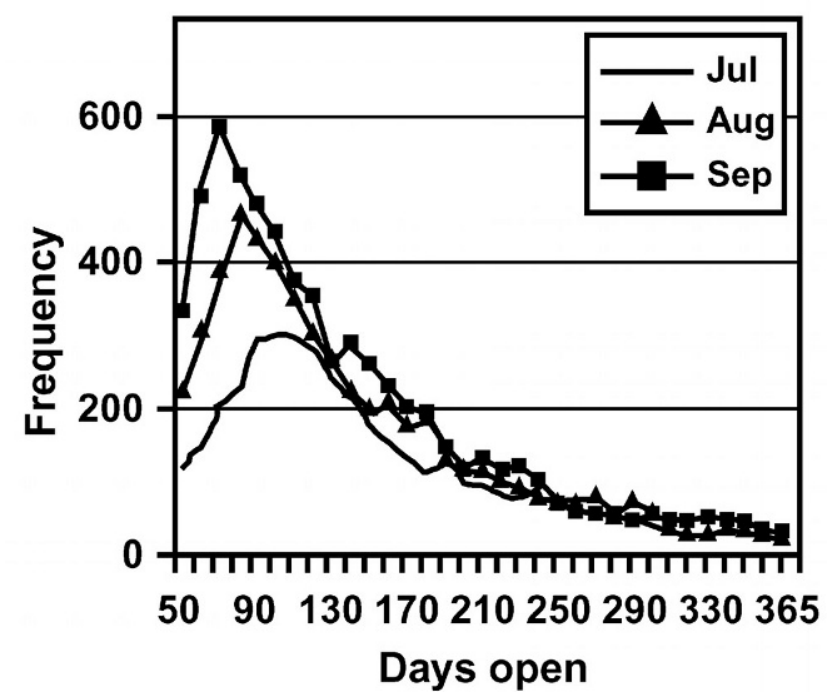

b)

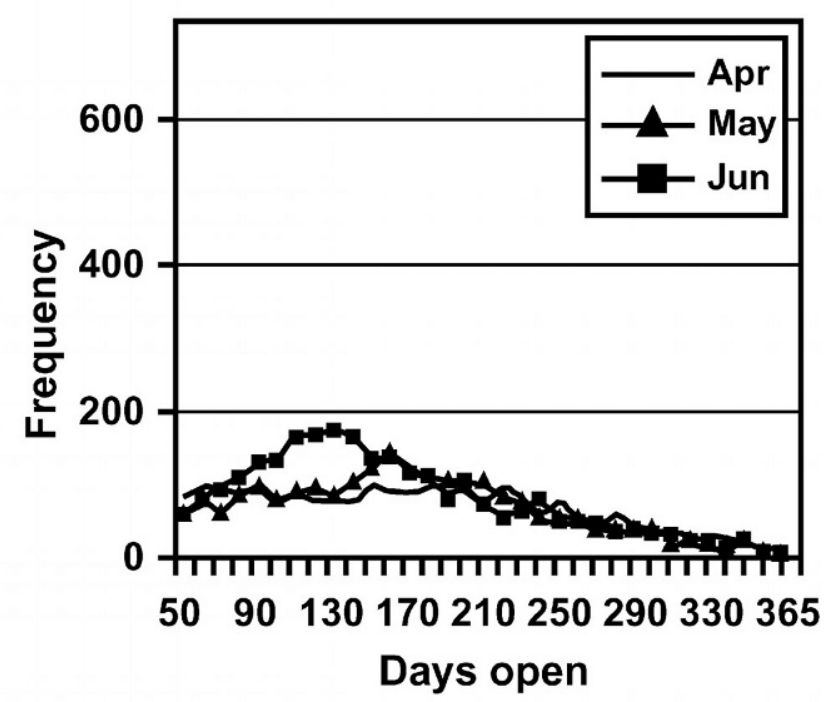

d)

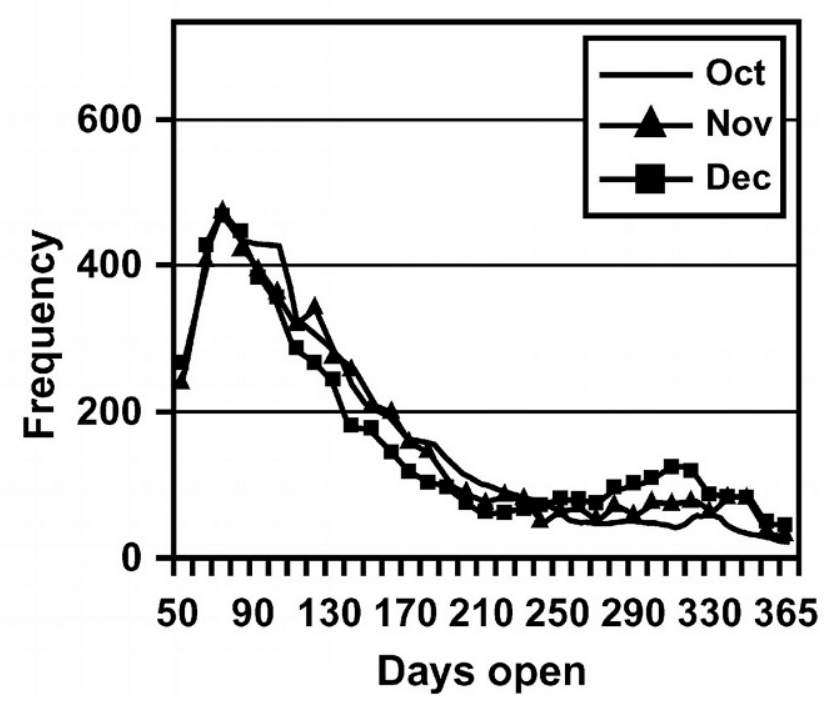

Figure 6. Distribution of days open in Georgia by month of calving: a) January-March, b) April-June, c) July-September, and d) October-December.

Figure 6 presents the distribution of DO in Georgia for different months of calving. For the July to October period, the distribution contains a sharp peak at around $80 \mathrm{~d}$ with a slow decline afterwards. Starting in November, a second peak appears at around $280 \mathrm{~d}$. For the next few months, the two peaks move closer, culminating in a single, wide peak for cows calving in April.

Seasonal patterns of monthly DO is to a large extent due to management decisions of not breeding animals during the hot season because of low fertility during this season (Ingraham et al., 1974; Badinga et al., 1985). For instance, a cow calving in March may be first bred in June. If that breeding is unsuccessful, it may be delayed until November. In such a case, distribution of DO would have a sharp peak corresponding to successful June breeding (circa $90 \mathrm{~d}$ ), and another peak corresponding to November breeding $(240 \mathrm{~d})$.

Figure 7 presents the distribution of DO for cows calving in the months of March and September for Texas, a state with high SOC, and for California and 
a)

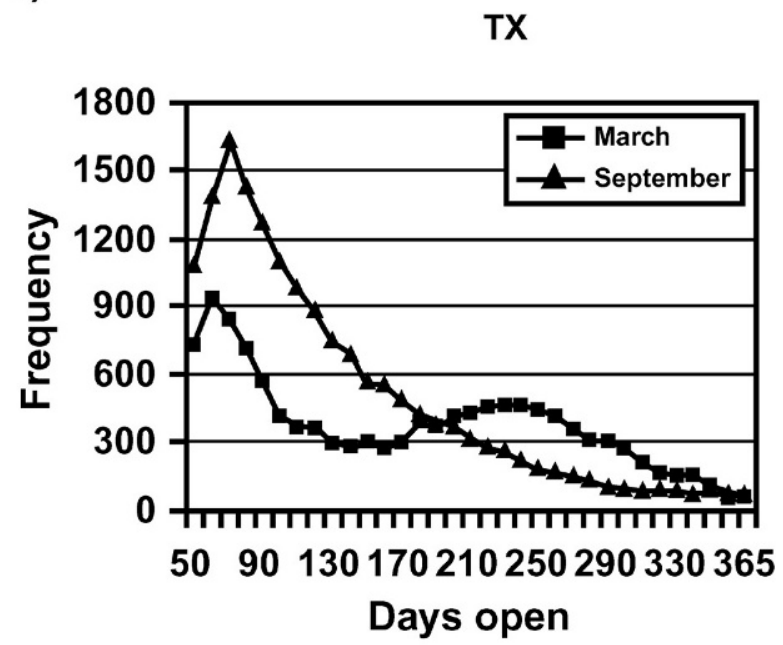

b)

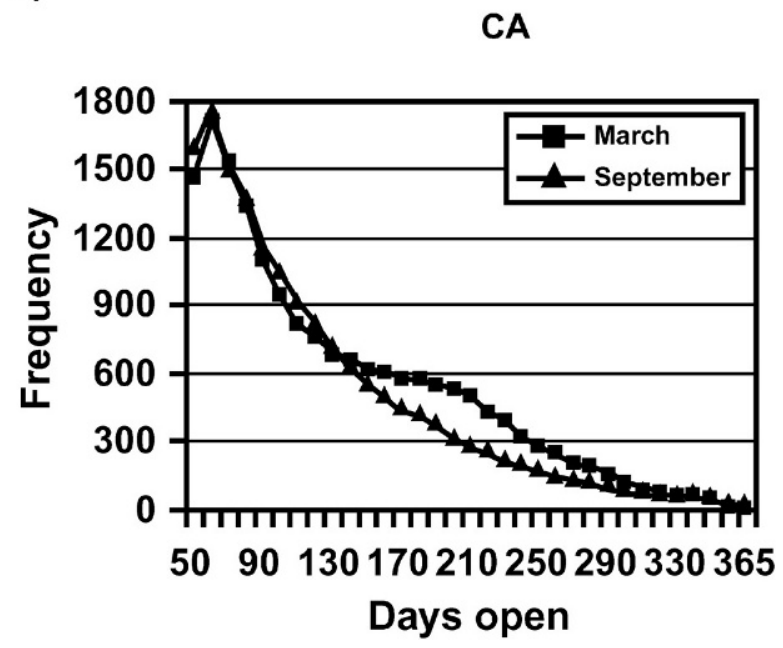

c)

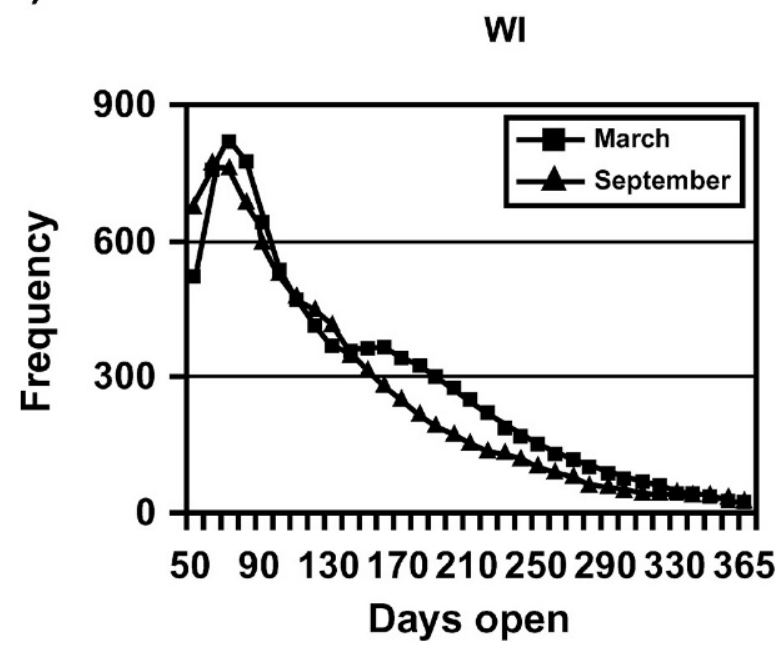

Figure 7. Distribution of days open for March and September calvings: a) Texas, b) California, and c) Wisconsin.
Wisconsin, which are states with low SOC. The distribution for March calvings is also bimodal for these states. However, the height of the second peak is smaller in California or Wisconsin than in Texas, perhaps due to unsuccessful inseminations, rather than delayed rebreeding. In contrast, September calvings for all three states show a long right tail and no double peaks. Thus, delayed breeding or depressed fertility due to seasonal factors seems to occur in many states although at different levels. Also, there is a growing perception by some herd owners that deliberate delayed breeding is a viable management and economic strategy in modern dairy management (Arbel et al., 2001; Washburn et al., 2002; Rajala-Schultz and Frazer, 2003). Thus, large DO may be due to delayed breeding and not necessarily be an indication of poor fertility.

Use of DO as an indicator of fertility in genetic evaluations may require a more sophisticated analysis. While very short DO indicate good fertility, large DO may be due to poor fertility or to delayed breeding. If a majority of cows cycle within $80 \mathrm{~d}$ and get pregnant within four cycles (of $21 \mathrm{~d}$ ), legitimate DO would be limited to about $\leq 164$ d. Records with larger DO could be considered outliers and edited out. In another procedure, each record would be assigned the probability of being due to delayed/nondelayed breeding, e.g., based on month of calving, location, and DO. Subsequent analysis would consider the two groups of records as being generated from a mixture distribution (McLachlan and Peel, 2000). The status delayed/nondelayed can be determined accurately for cows for which all insemination records are available. In addition, the use of actual estrus detection records would also facilitate the above process.

\section{CONCLUSIONS}

Days open is a complex trait that is influenced by regional and seasonal variations. Heat stress in the form of seasonal breeding and high variation of days open is most present in the Southeast, parts of the Southwest, and Midwest. A very high number of days open does not necessarily reflect poor fertility, since it could also be result of sound management decisions. Potential genetic evaluation for days open as a fertility trait should consider those decisions, e.g., by a sophisticated statistical model.

\section{ACKNOWLEDGMENTS}

Data were provided by the AIPL of the USDA. Paul VanRaden and Melvin Tooker provided insight about the data structure and formats. Jarmila Bohmanova assisted with some of the charts. We acknowledge use- 
ful discussions with B. Graves and J. West. Finally, we acknowledge the financial support from the USDA grant No 2001-5101-11318.

\section{REFERENCES}

Arbel, R., Y. Bigun, E. Ezra, H. Sturman, and D. Hojman. 2001. The effect of extended calving intervals in high lactating cows on milk production and profitability. J. Dairy Sci. 84:600-608.

Badinga, L., R. J. Collier, W. W. Thatcher, and C. J. Wilcox. 1985. Effects of climate and management factors on conception rate of dairy cattle in subtropical environment. J. Dairy Sci. 68:78-85.

Cavestany, D., A. B. El-Wishy, and R. H. Foote. 1985. Effect of season and high environmental temperature on fertility of Holstein cattle. J. Dairy Sci. 68:1471-1478.

Faust, M. A., B. T. McDaniel, O. W. Robinson, and J. H. Britt. 1988. Environmental and yield effects on reproduction in primiparous Holsteins. J. Dairy Sci. 71:3092-3099.

Gwazdauskas, F. C., J. A. Lineweaver, and W. E. Vinson. 1981. Rates of conception by artificial insemination of dairy cattle. J. Dairy Sci. 64:358-362.

Hermas, S. A., C. W. Young, and J. W. Rust. 1987. Genetic relationships and additive genetic variance of productive and reproductive traits in Guernsey dairy cattle. J. Dairy Sci. 70:1252-1257.

Ingraham, R. H., D. D. Gillette, and W. D. Wagner. 1974. Relationship of temperature and humidity to conception rate of Holstein cows in subtropical climate. J. Dairy Sci. 57:476-481.

Lucy, M. C, and B. M. Crooker. 2001. Physiological and genetic differences between low and high index dairy cows. Pages 223-236 in Fertility in the High Producing Dairy Cow. Br. Soc. Anim. Sci. Occasional Publication No. 26 Vol. 1, Calway, Ireland.

McLachlan, G. J., and D. Peel. 2000. Finite Mixture Models. Wiley, New York, NY.

Monty, D. E., and L. K. Wolff. 1974. Summer heat stress and reduced fertility in Holstein-Friesian cows in Arizona. Am. J. Vet. Res. 35:1495-1500.

Nebel, R. L., and M. L. McGilliard. 1993. Interactions of high milk yield and reproductive performance in dairy cows. J. Dairy Sci. 76:3257-3268.

Norman, H. D., R. H. Miller, P. M. VanRadden, and J. R. Wright. 2002. Genetic relationships among fertility traits of Holsteins and Jerseys. http: aipl.arsusda.gov/publish/present.htm\#2002. Accessed march 2003.

Oleggini, G. H., L. O. Ely, and J. W. Smith. 2001. Effect of herd size on dairy herd performance parameters. J. Dairy Sci. 84:1044-1050.

Pryce, J. E., and R. F. Veerkamp. 2001. The incorporation of fertility indices in genetic improvement programs. Pages 237-249 in Fertility in the High-Yielding Dairy Cow. British Society of Animal Science Occasional Publications Number 26, Vol. 1, Galway, Ireland.

Rajala-Schultz, P. J., and G. S. Frazer. 2003. Reproductive performance in Ohio dairy herds in the 1990s. Anim. Reprod. Sci. 76:127-142.

Ray, D. E., A. H. Jassim, D. V. Armstrong, F. Wiersma, and J. D. Shuh. 1992. Influence of season and microclimate on fertility of dairy cows in a hot-arid environment. Int. J. Biomet. 36:141-145.

SAS User's Guide: Statistics. Version 8 Edition. 1999. SAS Inst., Inc., Cary, NC.

SeyKora, A. J., and B. T. McDaniel. 1983. Heritabilities and Correlations of lactation yields and fertility for Holsteins. J. Dairy Sci. 66:1486-1493

Silvia, W. 1998. Changes in reproductive performance of Holstein dairy cows in Kentucky from 1972 to 1996. J. Dairy Sci. 81(Suppl. 1):244. (Abstr.)

Stott, G. H. 1961. Female and breed associated with seasonal fertility variation in dairy cattle. J. Dairy Sci. 44:1698.

Stevenson, J. S., M. K. Schmidt, and E. P. Call. 1983. Factors affecting reproductive performance of dairy cows first inseminated after five weeks post partum. J. Dairy Sci. 66:1148.

Thatcher, W. W. 1974. Effects of season, climate and temperature on reproduction and lactation. Dairy Sci. 57:304-310.

VanRaden, P. M., A. Sanders, M. Tooker, R. Miller, and D. Norman. 2002. Daughter pregnancy rate evaluation of cow fertility. In: AIPL Presentations accessed in: http://aipl.arsusda.gov/ reference/fertility/DPR_rpt.htm \#DPR

Washburn, S. P., W. J. Silva, C. H. Brown, B. T. McDaniel, and A. J. McAllister. 2002. Trends in reproductive performance in Southeastern Holstein and Jersey DHI Herds. J. Dairy Sci. 85:244-251.

Weller, J. I., and M. Ron. 1992. Genetic analysis of fertility traits in Israeli Holsteins by linear and threshold models. J. Dairy Sci. 75:2541-2548.

Wolfenson, D., Z. Roth, and R. Meidan. 2000. Impaired reproduction in the heat stressed cattle: basic and applied aspects. Anim. Reprod. Sci. 60-61:535-547. 